\title{
VHL-42: 65-76(V74G) Peptide
}

National Cancer Institute

\section{Source}

National Cancer Institute. VHL-42: 65-76(V74G) Peptide. NCI Thesaurus. Code C38122.

A peptide vaccine consisting of amino acids 65 through 76 derived from the tumor suppressor protein Von Hippel-Lindau (VHL) with a glycine substitution at position 74. As a cancer vaccine, VHL-59: 65-76(V74G) may stimulate a cytotoxic T-lymphocyte (CTL) response against tumor cells expressing this VHL mutant protein. 